\title{
Detection of Plasmodium knowlesi DNA in the urine and faeces of a Japanese macaque (Macaca fuscata) over the course of an experimentally induced infection
}

\author{
Satoru Kawai ${ }^{1 *}$, Megumi Sato ${ }^{2}$, Naoko Kato-Hayashi ${ }^{1}$, Hisashi Kishi ${ }^{3}$, Michael A Huffman ${ }^{4}$, Yoshimasa Maeno ${ }^{5}$,
} Richard Culleton ${ }^{6}$ and Shusuke Nakazawa ${ }^{7}$

\begin{abstract}
Background: Diagnostic techniques based on PCR for the detection of Plasmodium DNA can be highly sensitive and specific. The vast majority of these techniques rely, however, on the invasive sampling of blood from infected hosts. There is, currently, considerable interest in the possibility of using body fluids other than blood as sources of parasite DNA for PCR diagnosis.
\end{abstract}

Methods: Urine and faeces were obtained from a Plasmodium knowlesi infected-Japanese macaque (Macaca fuscata) over the course of an experimentally induced infection. P. knowlesi DNA (PkDNA) extracted from urine and faeces were monitored by nested PCR targeting the $P$. knowlesi specific cytochrome $b$ (cytb) gene.

Results: Urinary PkDNA was detected on day 2, but was not amplified using DNA templates extracted from the samples on day 4, day 5 and day 6 . Subsequently, urinary PkDNA was detected from day 7 until day 11, and from day 20 until day 30. PkDNA in faeces was detected from day 7 until day 11, and from day 20 until day 37. Moreover, real-time quantitative PCR showed a remarkable increase in the amount of urinary PkDNA following anti-malarial treatment. This might have been due to the release of a large amount of PkDNA from the degraded parasites as a result of the anti-malarial treatment, leading to excretion of PkDNA in the urine.

Conclusions: The cytb-PCR system using urine and faecal samples is of potential use in molecular epidemiological surveys of malaria. In particular, monkey faecal samples could be useful for the detection of zoonotic primate malaria in its natural hosts.

Keywords: Plasmodium knowlesi, Zoonotic malaria, Japanese macaque, Urine, Faeces, Nested PCR, Cytochrome b, Chloroquine sulphate

\section{Background}

To date, microscopic examination of Giemsa-stained blood smears remains the most common and most trusted technique for the detection of malaria parasites. There are many alternative methods for parasite detection, each with their own strengths and weaknesses compared to microscopy. These include various techniques, such as rapid immuno-chromatographic tests that detect circulating

\footnotetext{
*Correspondence: skawai@dokkyomed.ac.jp

'Laboratory of Tropical Medicine and Parasitology, Dokkyo Medical University, Mibu, Tochigi 321-0293, Japan

Full list of author information is available at the end of the article
}

malaria antigens or antibodies; and polymerase chain reaction (PCR)-based assays for the detection of parasite DNA in peripheral blood [1]. Although these techniques are now available for diagnosing malaria, current approaches rely on the drawing of blood by finger pricking or venipuncture. The requirement for repeated drawing of blood samples for longitudinal follow-up studies or continuous monitoring in the case of vaccine efficacy tests may at times result in poor compliance, especially among infants, young children and pregnant women [2]. In addition, the procedure for drawing blood, if not carried out under stringent conditions, is associated with the risk of acquiring needle-borne 
infections, such as hepatitis B virus and human immunodeficiency virus [3]. Therefore, the development of noninvasive approaches using body fluids other than blood would improve malaria diagnosis and the completion of epidemiological surveys. It is also likely that noninvasive approaches to surveillance would improve population coverage.

Plasmodium knowlesi is a simian malaria parasite the natural hosts of which long-tailed macaques (Macaca fascicularis), pig-tailed macaques (Macaca nemestrina), and banded leaf monkeys (Presbytis malalophos), all of which inhabit large areas of Southeast Asia [4]. Following the report in 2004 of a large focus of human infections with $P$. knowlesi in Peninsular Malaysia, zoonotic $P$. knowlesi infections were described from numerous countries in Southeast Asia [4,5]. Human P. knowlesi infection may often have been misidentified by microscopy as Plasmodium malariae or Plasmodium falciparum due to morphologic similarities, leading to underestimations of its true prevalence [4]. Thus, PCR-based assays and sequence analysis are probably the most reliable methods of identifying $P$. knowlesi infection. Wide-scale surveys based on PCR are required to assess the prevalence and distribution of the reservoir hosts of zoonotic primate malaria. To date, epidemiological surveys involving the natural hosts of $P$. knowlesi rely on the detection of parasite DNA extracted from fresh, frozen or dried blood obtained from wild monkeys [6,7]. As invasive sampling of non-human primates is problematic both practically and ethically, non-invasive sampling methods are desirable.

Recent studies have shown that the saliva, urine and faeces of malaria patients contain trace amounts of Plasmodium DNA that is amplifiable by PCR and, therefore, could be used as an alternative source of specimens for epidemiological surveys [8-13]. Detection of parasite DNA fragments in urine by PCR has also been employed in the diagnosis of various other parasitic diseases, such as those caused by Toxoplasma gondii, Leishmania spp., Trichomonas vaginalis, Entamoeba histolytica, and Schistosoma mansoni, although at present it is still not widely used [14-18]. Despite the lower sensitivity of PCR for the detection of parasite DNA from urine and faeces compared to blood, noninvasive sampling may be preferable due to ease of use. Moreover, if parasite DNA can be detected using the excreta of free-living monkeys, it will provide a useful tool for epidemiological surveys on zoonotic primate malaria. Here, the detection of $P$. knowlesi DNA (PkDNA) in urine and faeces obtained from a Japanese macaque (Macaca fuscata) over the course of an experimentally induced infection is demonstrated. The relationship between parasitaemia and the detection of $P k D N A$ in both faeces and urine is analysed, and the diagnostic performance of $P k D N A$ detection is assessed.

\section{Methods}

\section{Animals and infection procedure}

A four-year-old $5.0 \mathrm{~kg}$ female Japanese macaque (Macacca fuscata), a second-generation offspring bred in captivity that had never been infected with malaria parasites, was used for this study. The animal was kept in an individual cage in a controlled environment at 25$27^{\circ} \mathrm{C}$ and $30-60 \%$ humidity, and given commercial food pellets supplemented with fresh fruits. Throughout the course of the experiment, investigators adhered to the Guidelines for the Use of Experimental Animals authorized by the Japanese Association for Laboratory Animal Science. The protocol was approved by the Committee on the Ethics of Animal Experiments of Dokkyo Medical University (Permit Number: 0656). The monkey was inoculated intravenously with $1 \times 10^{9}$ frozen $P$. knowlesi H strain (ATCC No. 30158) parasitized red blood cells (PRBCs) obtained from another infected Japanese macaque. Thin blood films were prepared from peripheral blood obtained through earpick at day $0,2,4,5,6,7,8$, $9,11,15,20,21,22,23,25,30,37,40,50$, and 60. Following Giemsa staining, parasitaemia was counted in a total $10^{4}$ erythrocytes with an optical microscope. Heparinized blood samples for DNA extraction and hematological examinations were obtained intravenously from the infected monkey on day $0,2,4,6,7,9,11,15$, $20,25,30,37,40,50$, and 60 . Whole blood samples for DNA extraction were stored at $-80^{\circ} \mathrm{C}$ until DNA extraction.

\section{Sampling procedures for urine and faeces}

Urine and faecal samples for DNA extraction were obtained from the infected monkey on days $0,2,4,5,6,7$, $8,9,10,11,12,15,20,21,22,25,30,37,40,50$, and 60 . A sampling net and tray were set under the monkey cage for three hours in the morning (9:00 AM12:00 PM) from which fresh urine and faeces were collected from the infected monkey (Additional file 1). They were replaced and cleaned thoroughly after every sampling to avoid contamination. Negative control samples were obtained from two non-infected monkeys (ID: J83 and J84) according to the same procedures. One gram of fresh faeces was mixed with $2.0 \mathrm{~mL}$ RNAlater ${ }^{\circledR}$ solution $\left(\right.$ Ambion $^{\circledR}$, Austin, TX), and the faecal and urine samples were promptly stored at $-80^{\circ} \mathrm{C}$ until DNA extraction. After thawing the urine samples, haemoglobin concentrations were measured using a commercial kit (Wako Pure Chemical Industries, Ltd., Osaka Japan). Bleeding due to menstruation was not observed during the experimental period.

\section{Anti-malarial treatment}

On the 7th day post-infection, an injectable solution of chloroquine sulphate $40 \mathrm{mg}$ (NIVAQUINE ${ }^{\mathrm{m}}$; Bangladesh 
Pharmaceutical Industry Lit, Dhaka, Bangladesh) was administered intramuscularly, followed by $20 \mathrm{mg}$ at $6 \mathrm{hr}$, $24 \mathrm{hr}$ and $48 \mathrm{hr}$ after initial administration for a total of $100 \mathrm{mg}$ (Figure 1). Parasitaemia dropped to submicroscopic levels from day 9 post-infection (two days following first drug treatment), but recrudesced at day 20 post-infection. On day 20 post-infection, $40 \mathrm{mg}$ of NIVAQUINE $^{\mathrm{TM}}$ was administered, followed by $20 \mathrm{mg}$ at $6 \mathrm{hr}, 12 \mathrm{hr}, 24 \mathrm{hr}$ and $48 \mathrm{hr}$ after first administration. On days 23, 24, 25 and 26, $20 \mathrm{mg}$ of NIVAQUINE ${ }^{\mathrm{Tm}}$ was administered to prevent recrudescence of the parasite (Figure 1).

\section{DNA extraction steps}

DNA was extracted from $100 \mu \mathrm{L}$ of each whole blood sample by using the Illustra ${ }^{\mathrm{Tm}}$ blood genomicPrep Mini Spin Kit (GE Healthcare, Buckinghamshire, UK) according to the manufacturer's instructions, and then eluted into $200 \mu \mathrm{L}$ of elution buffer for the kit. DNA extraction from urine samples was performed with a QIAamp Viral RNA Mini Kit (Qiagen, Hilden, Germany) according to the manufacturer's instructions. Briefly, $4 \mathrm{~mL}$ of urine sample was applied to the centrifugal filter units (Amicon Ultra-15, Millipore Ireland B.V., County Cork, Republic of Ireland), followed by centrifugation for 10 minutes at $2,000 \times g .200 \mu \mathrm{L}$ of the concentrated samples were applied to QIAam ${ }^{\odot}$ spin columns and centrifuged. After two washes, DNA was eluted with $80 \mu \mathrm{L}$ of the supplied buffer at room temperature. DNA extraction from faecal samples ( $1 \mathrm{~g}$ of faeces/2 ml RNAlate ${ }^{\odot}$ ) was performed with QIAamp ${ }^{\circ}$ DNA Stool Mini Kit (Qiagen) according to the manufacturer's instructions, and then eluted into $50 \mu \mathrm{L}$ of elution buffer for the kit. DNA extractions from each sample were performed within one month of the sampling, and the purity and concentration of DNA samples were determined using NanoDrop apparatus (Thermo Fisher Scientific, Waltham, MA). DNA was stored at $-20^{\circ} \mathrm{C}$ until use.

\section{Nested PCR for amplification of PkDNA}

Nested PCR (nPCR) was performed using a TaKaRa PCR Thermal Cycler Dice (TAKARA BIO INC. Shiga, Japan). Detection of PkDNA in blood, urine and faeces was performed by nPCR targeting the mitochondrial cytochrome $b$ gene $(c y t b)$. Primers for the primary PCR were Plasmodium genus-specific and those for secondary PCR were specific for P. knowlesi. Forward primers for the primary and secondary PCRs were as reported by Putaporntip et al. and the reverse primers were as reported by Tanizaki et al. [12,19]. DNA amplification was carried out in a total volume of $20 \mu \mathrm{L}$ containing $1 \mu \mathrm{L}$ of DNA template, $10 \mu \mathrm{L}$ of $2 \mathrm{X}$ PCR buffer (AmpliTaq Gold PCR Master Mix, AB Applied Biosystems, Branchburg, NJ, USA), and $0.3 \mu \mathrm{M}$ of each primer. Final volume of original samples per each PCR was as follows; blood was $0.5 \mu \mathrm{L}$; urine was $50 \mu \mathrm{L}$; faeces was $50 \mathrm{mg}$. Primary amplification conditions were as follows: initial denaturation at $95^{\circ} \mathrm{C}$ for $5 \mathrm{~min}$, followed by 35 cycles $\left(94^{\circ} \mathrm{C}\right.$ for $40 \mathrm{sec}, 50^{\circ} \mathrm{C}$ for $30 \mathrm{sec}$ and $72^{\circ} \mathrm{C}$ for $30 \mathrm{sec}$ ) and final extension at $72^{\circ} \mathrm{C}$ for 4 min. The product was diluted 1:50 in DEPC treated water (Invitrogen, Carlsbad, CA, USA), and $2 \mu \mathrm{L}$ of the diluted product was subsequently subjected to secondary amplification. The concentration of the primers and other constituents for secondary amplification was identical to those of the primary amplification. Secondary amplification conditions consisted of 25 cycles under the same conditions as the primary PCR, followed by a final extension at

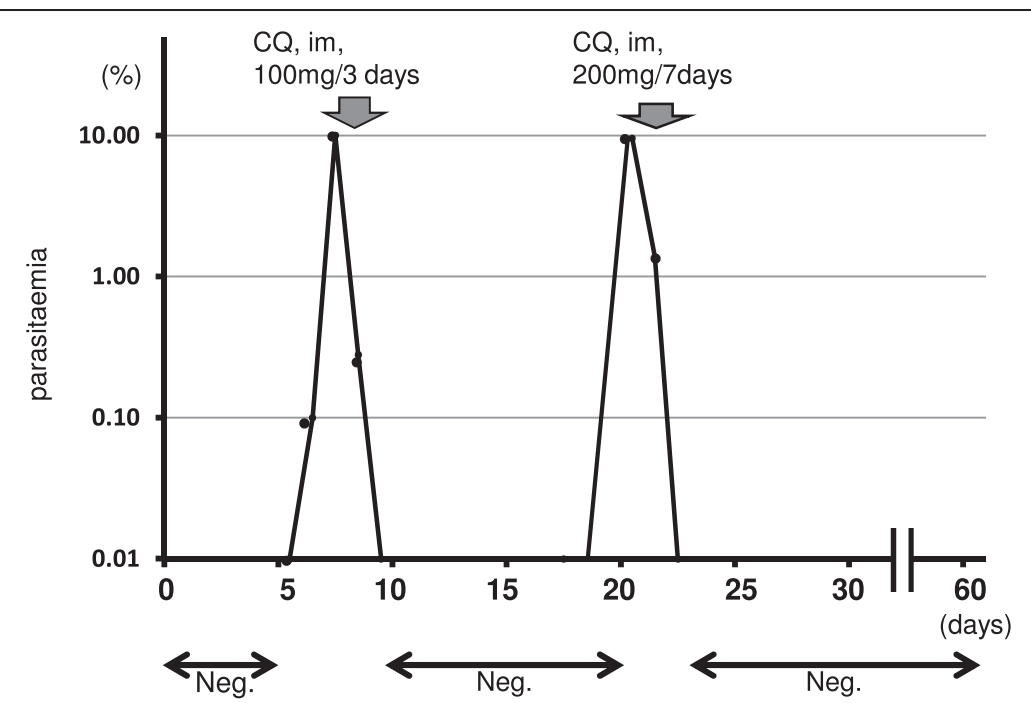

Figure 1 Parasitaemia during the course of infection. The arrows indicate chloroquine treatment. $\longleftrightarrow$ : Parasite negative in peripheral blood by microscopy. 
$72^{\circ} \mathrm{C}$ for $4 \mathrm{~min}$. A total of $10 \mu \mathrm{L}$ of PCR products were visualized by gel electrophoresis on a $2 \%$ agarose gel.

\section{Real-time quantitative PCR}

To measure the amount of PkDNA in the urine after anti-malarial treatment, quantitative nested real-time PCR (qPCR) was carried out. The qPCR in this study was designed referring to a previous report on diagnosis of Barmah forest virus infection by a nested real-time SYBR green RT-PCR assay [20]. Urine samples for qPCR were collected from the monkey prior to and following administration of the first and second anti-malarial treatment (Figure 1). The first set of urine samples was collected on day 5 , day $6,10: 00$ on day $7,16: 00$ on day $7,10: 00$ on day 8 and on day 10, and the second set of urine samples was collected on day $19,10: 30$ on day $20,16: 30$ on day 20 , $10: 30$ on day 21 , day 22 and day 23. qPCR was conducted using the first PCR products obtained from genus specific PCR used as a DNA template. All samples were tested in triplicate. The PCR mix consisted of $12.5 \mu \mathrm{L} \mathrm{SYBR}^{\oplus}$ Premix Ex Taq ${ }^{\text {Tm }}$ II, Tli RNaseH Plus (TAKARA BIO INC.), $0.4 \mu \mathrm{M}$ of each primer (e.g., PkCBF and PkCBR-ed) $[12,19]$, and $2 \mu \mathrm{L}$ of template DNA in a $25 \mu \mathrm{L}$ final reaction mix. PCR was performed in a Thermal Cycler Dice ${ }^{\oplus}$, Real Time System II (TAKARA BIO INC.) under the following conditions: 30 seconds at $95^{\circ} \mathrm{C}$ for initial denaturation, followed by 40 cycles $\left(95^{\circ} \mathrm{C}\right.$ for $5 \mathrm{sec}$ and $50^{\circ} \mathrm{C}$ for $30 \mathrm{sec})$ with melting curve analysis $\left(95^{\circ} \mathrm{C}\right.$ for $15 \mathrm{sec}, 60^{\circ} \mathrm{C}$ for $30 \mathrm{sec}$ and $95^{\circ} \mathrm{C}$ for $15 \mathrm{sec}$ ).

\section{Standard curve for qPCR}

To produce the standard curve for qPCR, genomic DNA of $P$. knowlesi $\mathrm{H}$ strain was prepared from infected blood obtained from another P. knowlesi-infected monkey (ID: J60). Parasitaemia in the blood was determined as $27 \%$. DNA extraction from infected blood was performed with the Illustra $^{\mathrm{Tm}}$ blood genomicPrep Mini Spin Kit according to the manufacturer's instructions. Final concentration of DNA dissolved in $200 \mu \mathrm{L}$ TE buffer was $57.6 \mathrm{ng} / \mu \mathrm{L}$. The DNA solution was diluted 1:1,000 with TE buffer, which was defined as $10^{4}$ "Plasmodial units (P units)". The standard curve for PkDNA was obtained from five serial dilutions $(57.6 \mathrm{ng} / \mu \mathrm{L} \times 1$, $57.6 \mathrm{ng} / \mu \mathrm{L} \times 10^{-1}, 57.6 \mathrm{ng} / \mu \mathrm{L} \times 10^{-2}, 57.6 \mathrm{ng} / \mu \mathrm{L} \times 10^{-3}$ and $\left.57.6 \mathrm{ng} / \mu \mathrm{L} \times 10^{-4}\right)$. Two negative controls consisted of sterile water. Primers for the first PCR were used PCBF and PCBR-ed [12,19]. The first PCR was carried out in a total volume of $20 \mu \mathrm{L}$ containing $1 \mu \mathrm{L}$ of DNA template, $10 \mu \mathrm{L}$ of $2 \mathrm{X}$ PCR buffer (AmpliTaq Gold PCR Master Mix), and $0.3 \mu \mathrm{M}$ of each primer. Primary amplification conditions were as follows: initial denaturation at $95^{\circ} \mathrm{C}$ for $5 \mathrm{~min}$, followed by 35 cycles $\left(94^{\circ} \mathrm{C}\right.$ for $40 \mathrm{sec}, 50^{\circ} \mathrm{C}$ for $30 \mathrm{sec}$ and $72^{\circ} \mathrm{C}$ for $30 \mathrm{sec}$ ) and final extension at $72^{\circ} \mathrm{C}$ for $4 \mathrm{~min}$. The first
PCR product was diluted 1:50 in DEPC treated water (Invitrogen), and $2 \mu \mathrm{L}$ of the diluted product was subsequently subjected to qPCR for the standard curve. The PCR mix consisted of $12.5 \mu \mathrm{L} \mathrm{SYBR}^{\oplus}$ Premix Ex $\mathrm{Taq}^{\mathrm{Tm}}$ II, Tli RNaseH Plus (TAKARA BIO INC.), $0.4 \mu \mathrm{M}$ of each primer (e.g., PkCBF and PkCBR-ed) $[12,19]$, and $2 \mu \mathrm{L}$ of template DNA in a $25 \mu \mathrm{L}$ final reaction mix. Secondary PCR for the standard curve was performed same condition as the sample analysis. Results of the qPCR are expressed in terms of "P units".

\section{Results}

\section{Parasitaemia and clinical examinations}

Parasites were first detected in the peripheral blood by microscopy on day 5 post infection, and, thereafter, parasitaemia increased sharply to around $10 \%$ on day 7 (Figure 1). On day 7, parasitaemia decreased markedly after initial treatment with $C Q$, and no parasites were detectable in the peripheral blood by microscopy from day 9 to day 15 postinfection. However, on day 20, parasitaemia rose to $9.53 \%$, and the monkey was administered anti-malarial drug once again (Figure 1). Parasitaemia decreased remarkably after this second treatment, with no second recrudescence observed for the remainder of the experiment. For this experiment, we monitored the kinetics of blood creatinine (CREA) and blood urea nitrogen (BUN) levels as an indicator of renal function (Table 1). On day 7, CREA and BUN levels experienced temporarily mild elevations as parasitaemia reached its primary peak; thereafter, levels ranged from 0.46 to $0.62 \mathrm{mg} / \mathrm{dL}$ (mean $\pm \mathrm{SD}: 0.55 \pm 0.04 \mathrm{mg} / \mathrm{dL}$ ) and 10.3 to $18.8 \mathrm{mg} / \mathrm{dL}(15.1 \pm 2.64)$, respectively. These concentrations were within the normal range of CREA $(0.81 \pm 0.28 \mathrm{mg} / \mathrm{dL})$ and BUN $(16.8 \pm 5.2 \mathrm{mg} / \mathrm{dL})$ in Japanese macaques [21]. In addition to blood haemoglobin levels, we monitored the kinetics of urinary haemoglobin levels (Table 1). On day 7 and 20, haemoglobin levels in the urine were elevated, correlating with increase in parasitaemia and with anti-malarial treatment. Urine samples that contained high haemoglobin concentrations showed a reddish colour.

\section{Detection of PkDNA from blood, urine and faeces}

The infection course was monitored by nPCR using DNA templates obtained from whole blood, urine and faeces. PkDNA was first detected in whole blood on day 2, where it remained detectable until day 25 post-infection (Figure 2). Urinary PkDNA was detected initially on day 2, but was not detected on day 4, day 5 and day 6 (Figure 3A). Subsequently, $P k D N A$ in urine was detected from day 7 until day 11, and from day 20 until day 30. Additionally, PkDNA in the faeces was detected from day 7 until day 11, and from day 20 until day 37 (Figure 3B). The negative control 
Table 1 Results of clinical examination over the course of the experiment

\begin{tabular}{|c|c|c|c|c|c|c|c|c|c|c|c|c|c|c|c|}
\hline \multicolumn{16}{|c|}{ Day after infection } \\
\hline & & 0 & 4 & 6 & 7 & 9 & 11 & 15 & 20 & 25 & 30 & 37 & 40 & 50 & 60 \\
\hline Para. & $\%$ & - & - & 0.1 & 10.08 & - & - & - & 9.58 & - & - & - & - & - & - \\
\hline WBC & $\times 10^{3} / \mu \mathrm{L}$ & 5.38 & 7.04 & 8.01 & 5.09 & 7.61 & 6.23 & 5.34 & 5.80 & 10.42 & 4.57 & 4.19 & 5.44 & 5.42 & 5.84 \\
\hline $\mathrm{RBC}$ & $\times 10^{4} / \mu \mathrm{L}$ & 512 & 471 & 481 & 403 & 329 & 302 & 327 & 312 & 258 & 327 & 401 & 403 & 452 & 428 \\
\hline$H G B$ & $\mathrm{~g} / \mathrm{dL}$ & 14.2 & 13.2 & 13.4 & 11.5 & 8.9 & 8.2 & 9.1 & 8.9 & 7.0 & 9.3 & 11.3 & 11.3 & 12.5 & 11.9 \\
\hline $\mathrm{HCT}$ & $\%$ & 44.4 & 40.8 & 41.7 & 36.6 & 29.5 & 26.8 & 29.2 & 29.6 & 24.8 & 31.1 & 37.7 & 37.3 & 39.1 & 37.4 \\
\hline MCV & $\mathrm{FI}$ & 86.7 & 86.6 & 86.7 & 90.8 & 89.7 & 88.7 & 89.3 & 94.9 & 96.1 & 95.1 & 94.0 & 92.6 & 86.5 & 87.4 \\
\hline $\mathrm{MCH}$ & $\mathrm{Pg}$ & 27.7 & 28.0 & 27.9 & 28.5 & 27.1 & 27.2 & 27.8 & 28.5 & 27.1 & 28.4 & 28.2 & 28.0 & 27.7 & 27.8 \\
\hline $\mathrm{MCHC}$ & $\%$ & 32.0 & 32.4 & 32.1 & 31.4 & 30.2 & 30.6 & 31.2 & 30.1 & 28.2 & 29.9 & 30.0 & 30.3 & 32.0 & 31.8 \\
\hline ALB & $\mathrm{g} / \mathrm{dL}$ & 4.7 & 4.4 & 4.4 & 3.5 & 3.3 & 3.3 & 3.6 & 3.1 & 3.1 & 3.2 & 3.9 & 3.8 & 4.1 & 3.9 \\
\hline AST & $\mathrm{IU} / \mathrm{L}$ & 27 & 24 & 27 & 51 & 42 & 31 & 24 & 52 & 50 & 25 & 23 & 28 & 30 & 19 \\
\hline ALT & $\mathrm{IU} / \mathrm{L}$ & 52 & 40 & 44 & 42 & 47 & 39 & 509 & 25 & 40 & 31 & 27 & 27 & 32 & 23 \\
\hline LD & $\mathrm{IU} / \mathrm{L}$ & 360 & 342 & 342 & 638 & 711 & 611 & 959 & 882 & 1277 & 533 & 302 & 569 & 489 & 265 \\
\hline ALP & IU/L & 790 & 892 & 909 & 704 & 973 & 1113 & 73 & 932 & 859 & 723 & 690 & 722 & 647 & 640 \\
\hline$\gamma-\mathrm{GTP}$ & IU/L & 96 & 84 & 88 & 68 & 70 & 63 & 0.51 & 69 & 67 & 72 & 84 & 81 & 90 & 82 \\
\hline $\mathrm{Cr}$ & $\mathrm{mg} / \mathrm{dL}$ & 00 & 0.69 & 0.66 & 0.82 & 0.53 & 0.46 & 14.3 & 0.62 & 0.54 & 0.53 & 0.55 & 0.58 & 0.59 & 0.59 \\
\hline BUN & $\mathrm{mg} / \mathrm{dL}$ & 0.67 & 15.4 & 16.9 & 22.2 & 10.3 & 11.2 & 0.1 & 13.6 & 16.9 & 15.1 & 16.2 & 18.0 & 16.6 & 18.8 \\
\hline BIL & $\mathrm{mg} / \mathrm{dL}$ & 13.9 & 0.1 & 0.1 & 0.2 & 0.1 & 0.2 & 0.01 & 0.05 & 0.1 & 0.1 & 0.1 & 0.1 & 0.1 & 0.1 \\
\hline BRP & $\mathrm{mg} / \mathrm{dL}$ & 0.01 & $<0.01$ & 0.03 & 7.89 & 6.26 & 0.25 & 0.01 & 10.40 & 0.24 & 0.01 & 0.01 & 0.01 & $<0.01$ & $<0.01$ \\
\hline U-HGB ${ }^{*}$ & $\mathrm{mg} / \mathrm{dL}$ & 56.8 & 57.9 & 58.4 & 102.0 & 65.0 & 65.0 & 68.3 & 213.6 & 62.8 & 54.5 & 54.0 & 60.1 & 52.8 & 52.8 \\
\hline
\end{tabular}

samples obtained from two non-infected monkeys showed negative reaction.

\section{Real-time quantitative PCR}

The standard curve constructed using five serial dilutions of the DNA solution showed good linearity with a consistent coefficient $(R 2=0.9892)$ (Additional file 2A). Melting curve analysis permitted the clear identification of PkDNA, as shown additional file $2 \mathrm{~B}$, and $\mathrm{T}_{m}$ values for each sample were highly reproducible during repeated melt curve runs. The quantity of PkDNA in urine samples collected from the monkey before, during, and after administration of anti-malarial treatment was measured by qPCR (Figure 4). The initial anti-malarial treatment started from 10:00 am on day 7 post-infection when parasitaemia was $10.08 \%$. The quantity of $P k D N A$ in urine increased around 50-fold (50.3 P units) 6 hours after initial administration (Figure 4A). Furthermore, when parasitaemia was $9.58 \%$ (at $10: 30$ on day 20), a second anti-malarial treatment course was initiated. The quantity of $P k D N A$ in urine increased around 10-fold (5.0 P units) 6 hours after administration (Figure 4B). Twenty-four hours from the start of

days after infection

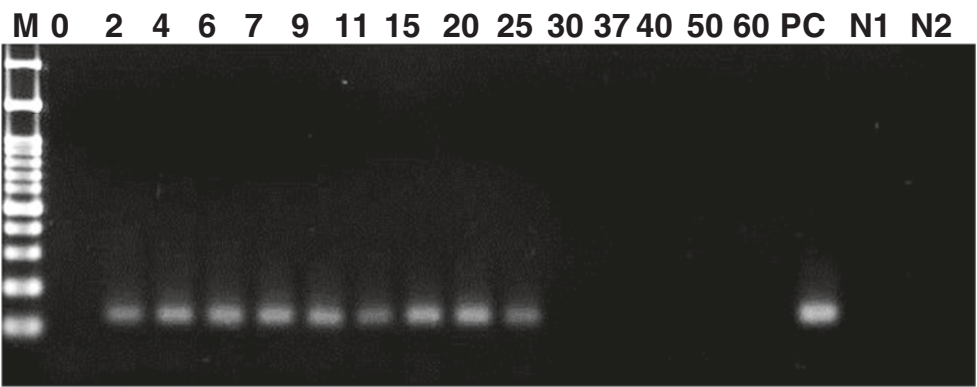

Figure 2 Detection of PkDNA in peripheral blood over the course of the experiment. PC: positive control, N1: negative control for 1st PCR, N2: negative control for 2nd PCR. 


\section{days after infection}

(A)

$\begin{array}{lllllllllllllllllllllllllll}M & 0 & 2 & 4 & 5 & 6 & 7 & 8 & 9 & 10 & 11 & 12 & 15 & 20 & 21 & 22 & 25 & 30 & 37 & 40 & 50 & 60 & \text { PC } & \text { N1 } & \text { N2 }\end{array}$

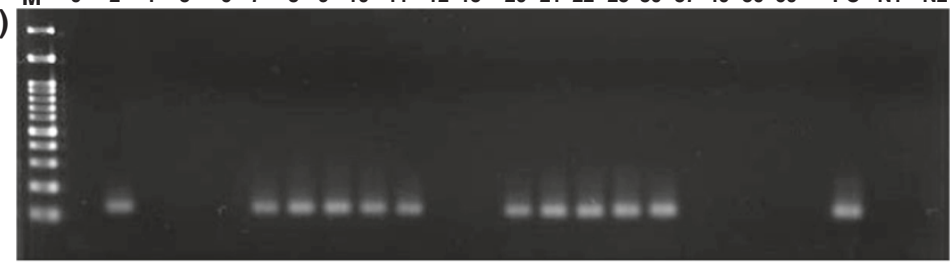

(B)

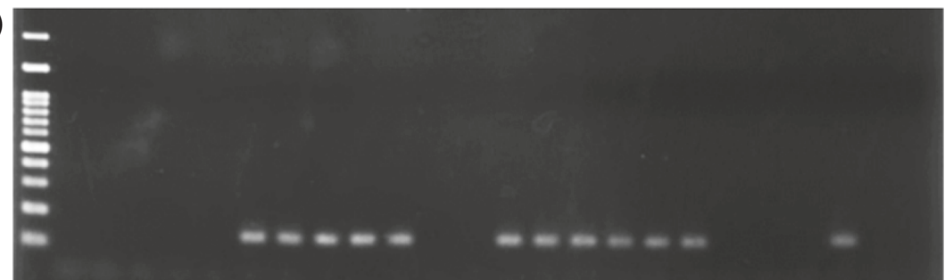

Figure 3 Detection of PkDNA in urine (A) and faecal samples (B) over the course of the experiment. PC: positive control, N1: negative control for 1st PCR, N2: negative control for 2nd PCR.

treatment for recrudescence, the concentration of PkDNA markedly increased by around 60-fold (297.0 P units), followed by a concurrent decrease with decreasing parasitaemia.

\section{Comparison between microscopy and nPCR}

A summary of parasite detection by microscopy and of $P k$ DNA by nPCR performed on gDNA extracted from blood, urine and faeces is shown in Figure 5. The detection period of the parasite by microscopy was markedly shorter than the detection of P $k$ DNA using nPCR. $P k$ DNA in blood, urine and faeces was detectable by nPCR, even when the erythrocytic stage of the parasite was not observable by microscopy. Moreover, PkDNA in faeces was detectable for a longer period than urinary PkDNA and PkDNA in the blood.

\section{Discussion}

Diagnostic techniques based on PCR for the detection of Plasmodium DNA can be highly sensitive and specific.

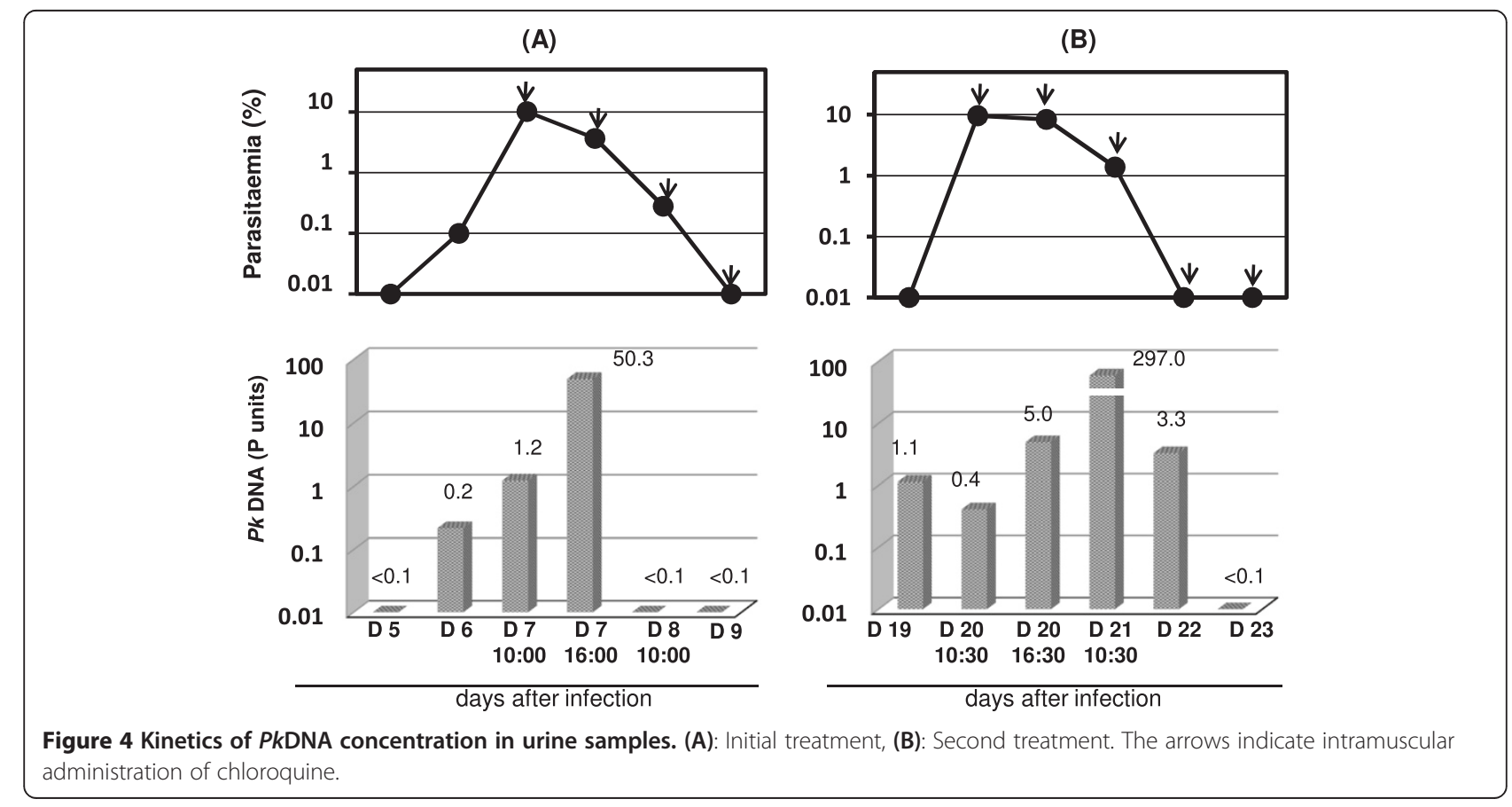




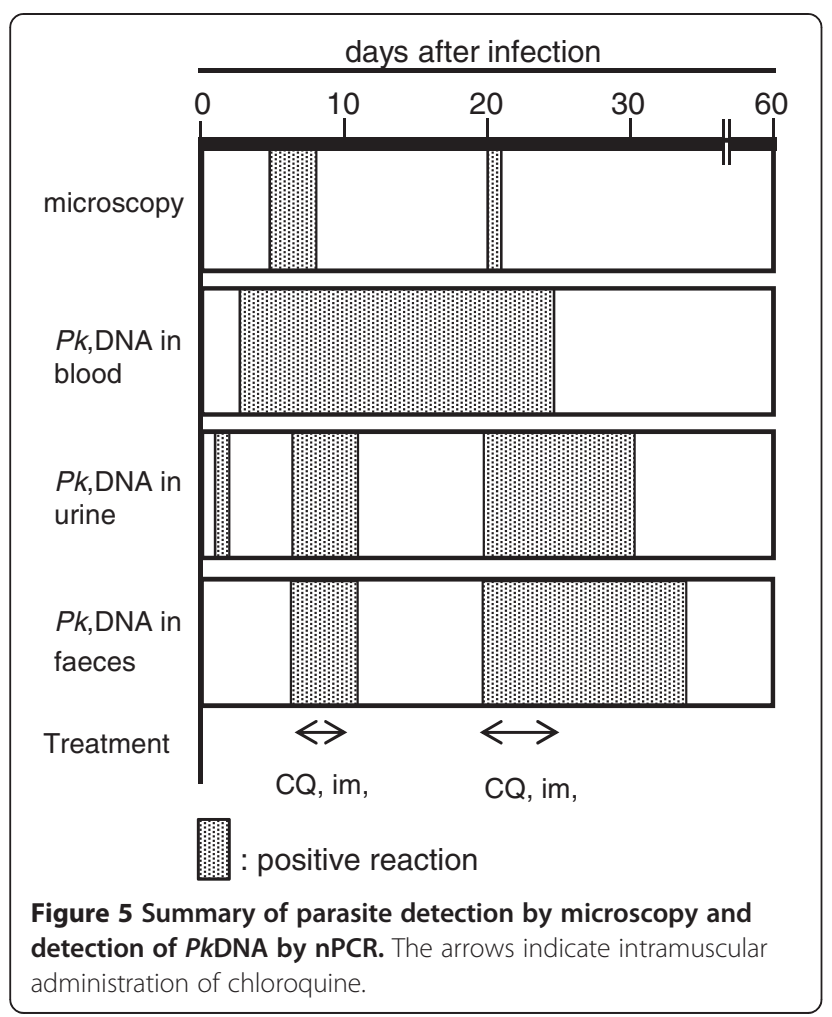

The vast majority of these techniques rely, however, on the invasive sampling of blood from infected hosts. Drawing blood for epidemiological surveys can cause considerable discomfort [2,3]. Accordingly, follow-up of patients using a less-invasive approach is desirable when conducting surveys of malaria prevalence. Recent studies have reported the detection of $P$. falciparum DNA (PfDNA) from saliva, urine and faecal samples, thus paving the way for a novel alternative source of specimens for potential malaria diagnosis [8-18]. These studies show that performing nPCR using PfDNA templates extracted from noninvasive samples had encouragingly high sensitivity and specificity, compared with microscopy of infected blood. In the present study, we were able to monitor the presence of PkDNA not only from blood samples, but also in urine and faeces were obtained from an infected Japanese macaque during a malaria episode.

Effective preservation of urine samples from malaria patients is a key factor influencing the performance of nPCR [11]. Furthermore, it has been suggested that ethanol preservation of urine samples is suitable for sample collection for field studies [11]. Although, in the present study, urine samples were not preserved in ethanol, they were promptly stored at $-80^{\circ} \mathrm{C}$, and the DNA extraction step was performed within a month of sampling. In addition, urine-derived DNA used as a PCR template was concentrated by centrifugal filter units prior to DNA extraction. A previous study using qPCR showed that the quantity of PfDNA detected in human urine was 2500-fold less than that from blood obtained concurrently from infected individuals [9]. It is believed that trace amounts of parasite DNA in urine can be significantly affected by various external factors such as microbial contamination and temperature conditions during sample preservation. It therefore appears that using suitable preservation methods and carrying out a DNA concentration step are important for the detection of parasite DNA in urine.

The release of Plasmodium DNA in urine could be a general phenomenon that occurs during the course of infection. However, since Plasmodium DNA may be released into the urine via various possible routes, the actual route of entry has not yet been precisely defined. In the present study, urinary PkDNA was first detected on day 2 after intravenous inoculation of frozen PRBCs, but was subsequently not detected on day 4, day 5 and day 6 . The urinary PkDNA seen on day 2 might have consisted of cell-free DNA from parasites that had degraded due to damage after thawing in the bloodstream. Moreover, qPCR results showed that the quantity of PkDNA in the urine increased markedly following anti-malarial treatment. This might have been due to the release of a large amount of PkDNA from the parasites that had been degraded following anti-malarial therapy, leading to excretion of PkDNA in the urine. Therefore, the main source of Plasmodium DNA in urine is likely to consist of circulating cell-free DNA originating from dying parasites in peripheral blood. These findings indicate that urine sampling is potentially useful for detecting malaria cases in longitudinal surveillance during, for example, anti-malarial drug trials. Although the relationship between low parasitaemia and urinary PkDNA level during chronic infection was not assessed here, the presence of PkDNA in the urine may be explained by the passage of parasite DNA fragments through the glomerulus as a result of normal renal function. Indeed, the kinetics of both BUN and CREA levels in the host stayed within their normal range during the experiment.

The simian parasite $P$. knowlesi has recently been found to be a major cause of malaria in humans in Malaysian Borneo, with the disease also reported in several Southeast Asian countries [4]. Epidemiological surveys of P. knowlesi infections in wild monkeys are very important for assessing the risk of zoonotic malaria. However, few studies exist on zoonotic primate malaria occurring under natural conditions since it is practically and ethically difficult to obtain blood samples from wild monkeys [6,7]. Faecal samples would, therefore, offer an attractive alternative method for the detection of primate malaria. Recently, phylogenetic analyses of DNA sequences from Plasmodium spp. have been conducted from faecal samples obtained from infected chimpanzees, gorillas, and bonobos [22-24]. The 
present study showed that PkDNA was detectable by nPCR from faecal samples obtained over the course of an infection. Detection was possible, even when the parasite's erythrocytic stage was not observable by microscopy. Our findings will provide basic data for future field surveys of P. knowlesi infection in free-living monkeys.

PkDNA in the blood was detected from day 2 until day 25 post-infection. As DNA was extracted from whole blood containing RBCs and sera, DNA from both intraerythrocytic parasites and parasite DNA fragments from the sera would be measured in this assay. PkDNA was detected in the faeces over a longer period than urinary PkDNA and the PkDNA obtained from blood. Parasite DNA may enter the faeces passively via serum or within the phagosomes of macrophages in the host's reticuloendothelial system. Another possibility is that cell-free DNA from degraded parasites in the liver enters the faeces via the bile. Recently, Abkallo and colleagues reported that DNA from the pre-erythrocytic stages of rodent malaria parasites was detectable in the liver, gall bladder and faeces of mice following sporozoite inoculation [25]. A particularly high concentration of parasite DNA was detected in the gall bladder. The authors concluded that parasite DNA entered the faeces via the bile following its clearance in the liver. Generally, infected erythrocytes are degraded not only in the spleen but also in the liver during the course of infection, and a large amount of degraded parasite constituents, including DNA, are produced in the liver. The degraded constituents are excreted from the liver via the bile to the faeces over a longer period compared to urine. It is possible that the parasite DNA is accumulated in gall bladder following parasite clearance, and it may be gradually excreted via the bile to the faeces. Whereas, the parasite DNA fragment through the glomerulus will not remain for very long in the urinary bladder, and it may be promptly excreted via the urine.

To date, molecular detection approaches using urine and faeces samples have been developed targeting several genes such as the merozoite surface protein-1 (MSP1) gene, MSP2 gene, DHFR gene, small subunit ribosomal RNA gene (18S rRNA) and the mitochondrial cytochrome $b$ (cytb) gene [8-13]. Putaporntip and colleagues demonstrated that the diagnostic performance of the $c y t b$-PCR system using saliva and urine could be of practical value in comparison with performing $18 S$ rRNA gene-PCR [12]. It is thought that the cytb-PCR system is highly sensitive, because it targets the mitochondrial genome, multiple copies of which are present in each parasite. Furthermore, Mharakurwa and colleagues showed that shorter PCR amplicons are amplified effectively from parasite DNA in urine and saliva because such DNA may be highly fragmented by the time it reaches these fluids [8]. This result has previously also been observed with amplified human DNA derived from frozen urine samples [26]. In the present study, a 131-bp sequence of the cytb gene of $P$. knowlesi could be detected in urine and faeces using a specific PCR assay. To further develop the PCR system for detection of parasite DNA in excreta, it is necessary to consider the target gene as well as its PCR amplicon size.

\section{Conclusion}

In conclusion, the $c y t b$-PCR system using urine and faecal samples is of potential use in molecular epidemiological surveys of malaria. Caution must be taken, however, when interpreting the results of positive amplification of malaria parasite DNA from faeces, as Abkallo et al. demonstrated that this could derive from liver stage parasites, and so does not necessarily prove that a host has, or is even susceptible to, a blood infection with these parasites [25]. Bearing this in mind, faecal samples could be useful for the detection of zoonotic primate malaria in its natural hosts. These findings, therefore, emphasize the potential usefulness of the $c y t b$-PCR system using urine and faeces as a tool for the surveillance of $P$. knowlesi infection in the field.

\section{Additional files}

Additional file 1: A sampling net and tray were set under the monkey cage.

Additional file 2: The standard curve of qPCR for PkDNA showing five 10 -fold serial dilutions (A). The melt curve from GPCR for PkDNA in urine samples (B).

\section{Abbreviations}

PkDNA: P. knowlesi DNA; PfDNA: P. falciparum DNA; Cytb: Cytochrome b.

\section{Competing interests}

The authors declare that they have no competing interests.

\section{Authors' contributions}

SK, MS, NK-H and HK collected and analyzed the samples, and were involved in drafting of the manuscript. MAH, YM, RC and SN coordinated the laboratory procedures and drafted the manuscript. All authors read and approved the final manuscript.

\section{Acknowledgments}

We are grateful to Ms. Mayumi Ohshita and Ms. Mayu Tanaka at the Laboratory of Tropical Medicine and Parasitology, Dokkyo Medical University for technical support. This study was supported in part by the following three grants: (i) the Japan Society for the Promotion of Science (JSPS) Asia Africa Science Platform Program, (ii) a Grant-in-Aid for Scientific Research No. 23406022 from the Japan Society for the Promotion of Science, (iii) Cooperative Research Grant (2012-24-6) of the Institute of Tropical Medicine, Nagasaki University.

\section{Author details}

'Laboratory of Tropical Medicine and Parasitology, Dokkyo Medical University, Mibu, Tochigi 321-0293, Japan. ${ }^{2}$ Graduate School of Health Sciences, Niigata University, Niigata, Japan. ${ }^{3}$ Laboratory of Hygiene, Dokkyo Medical University, Mibu, Tochigi, Japan. ${ }^{4}$ Section of Social Systems Evolution, Primate Research Institute, Kyoto University, Inuyama, Aichi, Japan. ${ }^{5}$ Department of Virology and Parasitology, Fujita Health University School of Medicine, Toyoake, Aichi, Japan. ${ }^{6}$ Malaria Unit, Institute of Tropical Medicine, Nagasaki University, Nagasaki, Japan. ${ }^{7}$ Department of Protozoology, Institute of Tropical Medicine, Nagasaki University, Nagasaki, Japan. 
Received: 30 July 2014 Accepted: 16 September 2014

Published: 19 September 2014

\section{References}

1. Hommel M: Diagnostic methods in malaria. In Essential Malariology. 4th edition. Edited by Warrell DA, Gilles HM. New York: Oxford University Press Inc; 2002:35-58

2. Sutherland $\mathrm{CJ}$, Hallett R: Detecting malaria parasites outside the blood. J Infect Dis 2009, 199:1561-1563.

3. Allain JP, Stramer SL, Carneiro-Proietti AB, Maetins ML, de Silva SN L, Ribeiro M, Proietti FA, Reesink HW: Transfusion-transmitted infectious diseases. Biologicals 2009, 37:71-77.

4. Singh B, Daneshvar C: Human infections and detection of Plasmodium knowlesi. Clin Microbiol Rev 2013, 26:165-183.

5. Singh B, Kim-Sung L, Matusop A, Radhakrishnan A, Shamsul SSG, Cox-Singh J, Thomas A, Conway DJ: A large focus of naturally aquired Plasmodium knowlesi infections in human being. Lancet 2004, 363:1017-1024.

6. Vythilingam I, NoorAzian YM, Tan CH, Yusri YM, AbdulHadi A, NorParina I, NoorRain A, LokmanHakim S: Plasmodium knowlesi in humans, macaques and mosquitoes in peninsular Malaysia. Parasit Vectors 2008, 1:26.

7. Jongwutiwes S, Buppan P, Kosuvin R, Seethamchai S, Pattanawong U, Sirichaisinthop J, Putaporntip C: Plasmodium knowlesi malaria in humans and macaques, Thailand. Emerg Infect Dis 2011, 17:1799-1806.

8. Mharakurwa S, Simoloka C, Thuma PE, Shiff CJ, Sullivan DJ: PCR detection of Plasmodium falciparum in human urine and saliva samples. Malar J 2006, 5:103.

9. Nwakanma D, Gomez-Escobar N, Walther M, Crozier S, Dubovsky F, Malkin E, Locke E, Conway: Quantitative detection of Plasmodium falciparum DNA in saliva, blood, and urine. J Infect Dis 2009, 199:1567-1574.

10. A-Elgayoum SM, El-Rayah EL-A, Giha HA: Towards a noninvasive approach to malaria diagnosis: detection of parasite DNA in body secretions and surface mucosa. J Mol Microbiol Biotechnol 2010, 18:148-155.

11. Buppan P, Putaporntip C, Pattanawong U, Seethamchai S, Jongwutiwes S: Comparative detection of Plasmodium vivax and Plasmodium falciparum DNA in saliva and urine samples from symptomatic malaria patients in a low endemic area. Malar J 2010, 9:72.

12. Putaporntip C, Buppan $P$, Jongwutiwes S: Improved performance with saliva and urine as alternative DNA sources for malaria diagnosis by mitochondrial DNA-based PCR assays. Clin Microbiol Infect 2011, 17:1484-1491.

13. Jirků M, Pomajbíková K, Petrželková KJ, Hůzová Z, Modrý D, Lukeš J: Detection of Plasmodium spp. in human feces. Emerg Infect Dis 2012 18:634-636

14. Nguyen TD, Kesel M, Bigaignon G, Hoet P, Pazzaglia G, Lammens M, Delmee M: Detection of Toxoplasma gondii tachyzoites and bradyzoites in blood, urine, and brains of infected mice. Clin Diagnos Lab Immunol 1996, 3:635-639.

15. Veland N, Espinosa D, Valencia BM, Ramos AP, Calderon F, Arevalo J, Low DE, Llanos-Cuentas A, Boggild AK: Polymerase chain reaction of Leishmania kDNA from the urine of Peruvian patients with cutaneous and mucocutaneous leishmaniasis. Am J Trop Med Hyg 2011, 84:556-561.

16. Pol BVD, Kraft CS, Williams JA: Use of an adaptation of a commercially available PCR assay aimed at diagnosis of chlamydia and gonorrhea to detect Trichomonas vaginalis in urogenital specimens. J Clin Microbiol 2006, 44:366-373.

17. Haque R, Kabir M, Noor Z, Rahman SMM, Mondal D, Alam F, Rahman I, Mahmood AA, Ahmed N, Petri WA Jr: Diagnosis of amebic liver abscess and amebic colitis by detection of Entoamoeba histolytica DNA in blood, urine, and sliva by a real-time PCR assay. J Clin Microbiol 2010, 48:2798-2801

18. Enk MJ, Silva GO, Rodrigues NB: Diagnostic accuracy and applicability of a PCR system for the detection of Schistosoma mansoni DNA in human urine samples from an endemic area. Plos One 2012, 7:e38947.

19. Tanizaki R, Ujiie M, Kato Y, Iwagami M, Hashimoto A, Kutsuna S, Takeshita N, Hayakawa K, Kanagawa S, Kno S, Ohmagari N: First case of Plasmodium knowlesi infection in a Japanese traveler returning from Malaysia. Malar J 2013, 12:128.

20. Hueston L, Toi CS, Jeoffreys N, Sorrell T, Gilbert G: Diagnosis of Barmah forest virus infection by a nested real-time SYBR green RT-PCR assay. PLoS One 2013, 8:e65197.
21. National Institute for Physiological Sciences, Technical Division: Normal values of blood and serum of Japanese monkeys (Macaca fuscata) by biochemical tests. [http://www.nips.ac.jp/tech/ipr/koike/Nihon_Monky/ NihonMonky_data.htm]

22. Prugnolle F, Durand P, Neel C, Ollomo B, Ayala FJ, Arnathau C, Etienne L, Mpoudi-Ngple E, Nkoghe D, Leroy E, Delaporte E, Peeters M: African great apes are natural hosts of multiple related malaria species, including Plasmodium falciparum. Proc Natl Acad Sci USA 2010, 107:1458-1463.

23. Liu W, Li Y, Learn GH, Rudicell RS, Robertson JD, Keele BF, Ndjango JBN, Sanz CM, Morgan DB, Locatelli S, Gonder MK, Kranzusch PJ, Walsh PD, Delaporte E, Mpoudi-Ngole E, Georgiev AV, Muller MN, Shaw GM, Peeters M, Sharp PM, Rayner JC, Hahn BH: Origin of the human malaria parasite Plasmodium falciparum in gorillas. Nature 2010, 467:420-425.

24. Liu W, Li Y, Shaw KS, Learn GH, Plenderleith LJ, Malenke JA, Sundararaman SA, Ramirez MA, Crystal PA, Smith AG, Bibollet-Ruche F, Ayouba A, Locatelli S, Esteban A, Mouacha F, Guichet E, Butel C, Ahuka-Mundeke S, Inogwabini BI, Ndjango JB, Speede S, Sanz CM, Morgan DB, Gonder MK, Kranzusch PJ, Walsh PD, Georgiev AV, Muller MN, Piel AK, Stewart FA, et al: African origin of the malaria parasite Plasmodium vivax. Nat Commun 2014, 5:3346. doi: 10.1038/ncomms4346.

25. Abkallo HM, Liu W, Hokama S, Ferreira PE, Nakazawa S, Maeno Y, Quang NT, Kobayashi N, Kaneko O, Huffman MA, Kawai S, Marchand RP, Carter R, Hahn $\mathrm{BH}$, Culleton R: DNA from pre-erythrocytic stage malaria parasites is detectable by PCR in the faeces and blood of hosts. Int J Parasitol 2014, 44:467-473

26. Hel OL, Luijit RB, Mesquita HBB, Noord PAH, Slothouber B, Roest M, Schouw YT, Grobbee DE, Pearson PL, Peeters PHM: Quality and quantity of DNA isolated from frozen urine in population-based research. Ana Biochem 2002, 304:206-211.

doi:10.1186/1475-2875-13-373

Cite this article as: Kawai et al:: Detection of Plasmodium knowlesi DNA in the urine and faeces of a Japanese macaque (Macaca fuscata) over the course of an experimentally induced infection. Malaria Journal 2014 13:373.

\section{Submit your next manuscript to BioMed Central and take full advantage of:}

- Convenient online submission

- Thorough peer review

- No space constraints or color figure charges

- Immediate publication on acceptance

- Inclusion in PubMed, CAS, Scopus and Google Scholar

- Research which is freely available for redistribution 